\title{
Secondary stroke prevention: misguided by guidelines?
}

\author{
Luk VANSTREELS ${ }^{1}$, Geert MOLENBERGHS², PhD; Jens-Uwe VOIGT ${ }^{3}$, PhD \\ ${ }^{1}$ University Hospitals of Leuven, Leuven, Belgium; ${ }^{2}$ Director of I-BioStat, Hasselt University and University Hospitals of Leuven, \\ Leuven, Belgium; ${ }^{3}$ Department of Cardiology, Head of Echocardiography, University Hospitals of Leuven, Leuven, Belgium.
}

Objectives Despite large clinical trials, there is no consensus about the best antithrombotic strategy for the secondary prevention of non-cardioembolic ischaemic stroke. This retrospective study is the first to combine the results of the most important trials and to integrate data on study validity, effectiveness, adverse events, risk of non-compliance, and cost.

Methods We searched MEDLINE, EMBASE, and the Cochrane Database (1996 to July 2011) and selected long-term secondary prevention trials with treatment with aspirin, dipyridamole, clopidogrel, aspirin plus dipyridamole, or aspirin plus clopidogrel. Subgroup analyses were included to explain differences in interpretations that could have led to the differences in guidelines.

Results Two trials showed a small but significant reduction with aspirin plus dipyridamole compared to aspirin (ARR $1.5 \%, P<0.05$ and ARR $1.0 \%$, $P<0.05$ ). There was no effect on vascular death. One trial showed a small but statistical significant reduction with clopidogrel compared to aspirin (ARR $0.5 \%, P<0.05)$. The association of clopidogrel with aspirin could not show any significant benefit compared to clopidogrel monotherapy, nor compared to aspirin monotherapy, but showed higher rates of adverse events. Significantly more patients discontinued treatment with aspirin plus dipyridamole compared to aspirin monotherapy (34.5\% versus $13.4 \%$ and $29.0 \%$ versus $22.2 \%, P<0.001)$ and clopidogrel monotherapy $(29.1 \%$ versus $22.6 \%, P<0.001)$. Transposition of statistical significant reductions in stroke recurrence into clinical significance could not be supported.

Conclusions Despite changes in international guidelines, aspirin monotherapy should retain its position as the main antiplatelet agent for secondary prevention of non-cardioembolic ischaemic stroke.

Keywords Aspirin-dipyridamole-clopidogrel-secondary prevention-stroke.

\section{INTRODUCTION}

Stroke recurs in up to $4 \%$ within the first week, $13 \%$ by one year and $30 \%$ by five years, reflecting the need for secondary prevention ${ }^{1}$. Aspirin, aspirin plus dipyridamole and clopidogrel monotherapy all have proved efficacy in the secondary prevention of non-cardioembolic ischaemic stroke. Despite large clinical trials there is no consensus about the best antithrombotic strategy: the American Stroke Association recommends the

Address for correspondence:

Luk Vanstreels, Winkelstrasse 20, 4730 Raeren, Belgium

E-mail: luk.vanstreels@uzleuven.be

Received 19 December 2011; revision accepted for publication

3 April 2012 combination of aspirin plus dipyridamole, the National Institute for Clinical Health and Excellence recommends clopidogrel and in Belgium, aspirin is the agent of choice $^{2-4}$. In contrast, the European Stroke Organisation recommends that where possible, aspirin plus dipyridamole, or clopidogrel alone should be given, whereas aspirin alone may be used as an alternative ${ }^{5}$. This retrospective study aims to address this question by a critical analysis of the literature and combining effectiveness, adverse events, and cost.

\section{METHODS}

We searched EMBASE, MEDLINE and the Cochrane Database using the search terms 'ischaemic stroke,' 'cerebrovascular accident', 'transient ischaemic attack', 'secondary prevention', 'antiplatelet therapy', 'aspirin', 'extended-release dipyridamole,' 'clopidogrel'. Only large 
randomized trials $(\mathrm{n}>1000)$ were included in which randomization occurred within six months after the qualifying event. Meta-analyses, subgroup analyses and guidelines were added based on relevance. Search was restricted from January 1st, 1996 to July 1st, 2011.

\section{RESULTS}

\section{Section 1: Clinical effectiveness}

Six large, randomized controlled trials (RCTs) were found: the 'Second European Stroke Prevention Study' (ESPS-2), the 'European/Australasian Stroke Prevention in Reversible Ischaemia Trial' (ESPRIT), the 'Clopidogrel versus Aspirin in Patients at Risk of Ischaemic Events' - trial (CAPRIE), the 'Management of Atherothrombosis with Clopidogrel in High-risk patients' trial (MATCH), the 'Clopidogrel for High Atherothrombotic Risk and Ischaemic Stabilization, Management and Avoidance'- trial (CHARISMA) and the 'Prevention Regimen for Effectively Avoiding Second Strokes'- trial

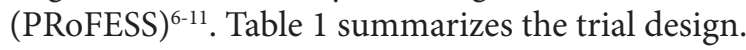

\section{Comparison 1: aspirin versus placebo}

According to the ESPS- 2 trial, stroke risk reduces by $18 \%$ with acetyl salicylic acid (ASA) (25 mg twice daily) compared to placebo in patients with a history of TIA or stroke $(n=3298)^{6}$. In a collaborative meta-analysis of the Antithrombotic Trialists' Collaboration, relative risk reduction was $25 \%$ for serious vascular events (non-fatal myocardial infarction, non-fatal stroke or vascular death) in patients at high risk of occlusive vascular events $(\mathrm{n}=135,000)^{12}$. No significant difference in primary outcome was reported among different doses (500$1,500 \mathrm{mg}$ versus $160-325 \mathrm{mg}$ versus $75-150 \mathrm{mg}$ ).

\section{Comparison 2: dipyridamole versus placebo}

The ESPS- 2 trial concluded that extended-release dipyridamole (200 mg twice daily), providing a relative stroke risk reduction of $16 \%$ compared to placebo, is as effective as aspirin for the secondary prevention of ischaemic stroke ${ }^{6}$.

\section{Comparison 3: clopidogrel versus placebo}

No RCT was found comparing clopidogrel versus placebo. The European Stroke Organisation gives a number needed to treat (NNT) of 62, based on a 1999 indirect comparison ${ }^{5,13}$.

\section{Comparison 4: aspirin plus dipyridamole versus placebo}

In the ESPS- 2 trial, the combination of ASA $(2 \times$ $25 \mathrm{mg})$ plus dipyridamole $(2 \times 200 \mathrm{mg})$ resulted in a relative risk reduction of $37 \%$ for stroke and $15 \%$ for

Table 1 Trial design

\begin{tabular}{|c|c|c|c|c|}
\hline & Drug (mg) & Patients & Primary end points & Secondary end points \\
\hline ESPS-26 (1996) & $\begin{array}{l}\text { ASA }(2 \times 25) \leftrightarrow D I P(2 \times 200) \leftrightarrow \\
\text { ASA }+ \text { DIP }(2 \times 25 / 2 \times 200) \leftrightarrow P L A\end{array}$ & $\begin{array}{l}\text { IS or TIA } \\
\mathrm{N}=6602 \\
\text { FU: } 2 \text { years }\end{array}$ & $\begin{array}{l}\text { Any stroke } \\
\text { Any death } \\
\text { Stroke and/or death }\end{array}$ & $\begin{array}{l}\text { TIA, MI, ischaemic events, other } \\
\text { vascular events }\end{array}$ \\
\hline ESPRIT' (2006) & $\begin{array}{l}\text { ASA }(30-325) \leftrightarrow \\
\text { ASA+DIP }(30-325 / 2 \times 200)\end{array}$ & $\begin{array}{l}\text { TIA or minor stroke of presumed } \\
\text { arterial origin } \\
N=2739 \\
F U: 3.5 \text { years }\end{array}$ & $\begin{array}{l}\text { Composite of vascular death, } \\
\text { non-fatal stroke, non-fatal MI, or } \\
\text { major bleeding complication }\end{array}$ & $\begin{array}{l}\text { Any death, vascular death, } \\
\text { vascular death and non-fatal } \\
\text { stroke, all major ischaemic events, } \\
\text { all vascular events, major bleeding } \\
\text { complication }\end{array}$ \\
\hline CAPRIE $^{8}(1996)$ & $\mathrm{CLO}(75) \leftrightarrow \mathrm{ASA}(325)$ & $\begin{array}{l}\text { IS, MI, or PAD } \\
N=19,185 \\
\text { FU: } 1-3 \text { years }\end{array}$ & $\begin{array}{l}\text { Composite of ischaemic stroke, Ml, } \\
\text { or vascular death }\end{array}$ & $\begin{array}{l}\text { Any combination with amputation } \\
\text { and vascular death only }\end{array}$ \\
\hline MATCH $^{9}(2004)$ & $\mathrm{ASA}+\mathrm{CLO}(75 / 75) \leftrightarrow \mathrm{CLO}(75)$ & $\begin{array}{l}\text { High-risk patients taking CLO with } \\
\text { recent IS or TIA } \\
\mathrm{N}=7599 \\
\text { FU: } 18 \text { months }\end{array}$ & $\begin{array}{l}\text { Composite of ischaemic stroke, Ml, } \\
\text { vascular death or rehospitalization } \\
\text { for acute ischaemic event }\end{array}$ & $\begin{array}{l}\text { Any combination with or without } \\
\text { any death and any stroke }\end{array}$ \\
\hline CHARISMA $^{10}(2006)$ & $\begin{array}{l}\mathrm{ASA}+\mathrm{CLO}(75-162 / 75) \leftrightarrow \\
\mathrm{ASA}(75-162)\end{array}$ & $\begin{array}{l}\text { Cardiovascular disease or multiple } \\
\text { RF } \\
N=15,603 \\
\text { FU: } 28 \text { months }\end{array}$ & $\begin{array}{l}\text { Composite of any stroke, Ml, or } \\
\text { vascular death }\end{array}$ & $\begin{array}{l}\text { Any stroke, } \mathrm{MI} \text {, vascular death, } \\
\text { hospitalization for unstable angor, } \\
\text { TIA or revascularization procedure }\end{array}$ \\
\hline PRoFESS ${ }^{11}(2008)$ & $\begin{array}{l}\text { ASA+DIP }(2 \times 25 / 2 \times 200) \leftrightarrow \\
\text { CLO (75) }\end{array}$ & $\begin{array}{l}\text { Recent } \mathrm{IS} \\
\mathrm{N}=20,332 \\
\mathrm{FU}: 2.5 \text { years }\end{array}$ & Any stroke & Any stroke, $\mathrm{Ml}$, or vascular death \\
\hline
\end{tabular}


stroke or death compared to placebo ${ }^{6}$. No significant effect on death alone was found. According to a Cochrane review, the relative risk (RR) was 0.74 (95\% CI, 0.680.80 ) for further vascular events and statistically not significant for vascular death alone ${ }^{14}$.

\section{Comparison 5: aspirin plus dipyridamole versus aspirin}

In the ESPS-2 trial, stroke risk was reduced by $23 \%$ after 24 months, but neither the combined primary end point 'stroke and/or death', nor 'death' alone reached statistical significance ${ }^{6}$. In the ESPRIT trial, the combination of aspirin (30-325 mg daily) plus dipyridamole (200 mg twice daily) resulted in an absolute risk reduction of $1.0 \%$ per year (95\% CI, $0.1-1.8$ ) for the composite of death from all vascular causes, non-fatal stroke, non-fatal myocardial infarction, or major bleeding complication ${ }^{7}$. According to the Cochrane review, relative risk was 0.87 (95\% CI, 0.79-0.96) for vascular events ${ }^{14}$. A 2008 meta-analysis showed a RR of 0.76 (95\% CI, 0.65-0.89) for stroke and a RR of 0.82 (95\% CI, 0.73-0.92) for the composite outcome of stroke, myocardial infarction or vascular death ${ }^{15}$.

\section{Comparison 6: clopidogrel versus aspirin}

According to the CAPRIE trial, clopidogrel (75 mg) was more effective than aspirin (325 $\mathrm{mg}$ ) in reducing the combined risk of ischaemic stroke, myocardial infarction, or vascular death with a relative risk reduction of $8.7 \%$ (95\% CI, 0.3-16.5) ${ }^{8}$.

\section{Comparison 7: clopidogrel plus aspirin versus aspirin}

The MATCH trial investigated the effect of adding $75 \mathrm{mg}$ of clopidogrel to $75 \mathrm{mg}$ of aspirin ${ }^{9}$. No significant difference was found for the primary composite end point of ischaemic stroke, myocardial infarction, vascular death, or rehospitalization for acute ischaemia (including rehospitalization for TIA, angina pectoris, or worsening of peripheral arterial disease).

\section{Comparison 8: clopidogrel plus aspirin versus clopidogrel}

In the CHARISMA study, clopidogrel $(75 \mathrm{mg}$ ) plus aspirin $(75-162 \mathrm{mg}$ ) was compared to clopidogrel monotherapy $(75 \mathrm{mg})^{10}$. There was no significant difference in the primary composite end point of myocardial infarction, stroke, or death from cardiovascular causes.

\section{Comparison 9: aspirin plus dipyridamole versus clopidogrel}

Until the publication of the PRoFESS trial in 2008, comparison of aspirin plus dipyridamole versus clopidogrel was based on assumptions and indirect comparisons. Using a network meta-analysis, Thijs et al. suggested a benefit of aspirin plus dipyridamole compared to clopidogrel (OR 0.84; 95\% CI 0.73-0.97) ${ }^{16}$. The PRoFESS trial did not meet the predefined criteria of non-inferiority, but showed similar rates of stroke recurrence with both therapies. Based on the only marginal difference in primary outcome (9.0\% versus $8.8 \%$; HR $1.01 ; 95 \%$ CI $0.92-1.11)$, the same secondary outcome events $(13.1 \%)$ and the inherent problems of defining the non-inferiority margin in non-inferiority trials, clinical equivalence can be suggested.

\section{SECTION 2: TOLERANCE}

In the ESPS-2 trial, statistical significance of adverse events was calculated for overall treatment comparison ${ }^{6}$. Any adverse event occurred in about $57 \%$ in the placebo group, $60 \%$ in the aspirin group and $64 \%$ in the aspirin plus dipyridamole group $(P<0.001)$. Significantly more gastro-intestinal events, headache and bleeding at any site occurred in the aspirin plus dipyridamole group, followed by aspirin and placebo $(P=0.042, P<0.001$ and $P<0.001$, respectively). A meta-analysis of 31 randomized controlled trials $(n=192,036)$ concluded that risk of haemorrhage differed among different doses of aspirin, being less for low doses $(<100 \mathrm{mg})$, compared to moderate (100-200 mg) and high doses (>200 mg), especially with regard to minor and gastro-intestinal (GI) bleedings ${ }^{17}$. Another meta-analysis (2006) showed that, although risk of major bleeding increased by $~ 70 \%$ with low-dose aspirin compared to placebo, absolute risk increase would be modest: 769 patients would be needed to treat to cause one additional major bleeding episode annually ${ }^{18}$. Compared to clopidogrel, risk of bleeding with aspirin only differed among GI bleeding (absolute annual increase $0.12 \%$ with aspirin).

In the CAPRIE trial, significantly more patients reported rash and diarrhoea with clopidogrel than with aspirin, while indigestion/nausea/vomiting and gastrointestinal haemorrhage were more frequently reported with aspirin than with clopidogrel ${ }^{8}$. Except for diarrhoea, these qualifying events led to significantly more permanent study drug discontinuation. A Cochrane review concluded in 2009 that clopidogrel would be at least as safe as aspirin, significantly reducing GI adverse effects (but increasing the odds of skin rash and diarrhoea) and 
could be used as an alternative in patients genuinely intolerant of or allergic to aspirin ${ }^{19}$.

Adverse events (especially bleeding complications) occurred even more frequently for the combination of aspirin plus clopidogrel, compared to each agent alone. In the CHARISMA trial, risk of primary intracranial haemorrhage and fatal bleeding did not statistically differ among the treatment groups, in contrast to risk of moderate bleeding, whereas in the MATCH trial, statistical significance was reached for life-threatening bleeding, major bleeding, and minor bleeding ${ }^{9,10}$.

The PRoFESS trial showed more haemorrhagic events for treatment with aspirin plus dipyridamole compared with clopidogrel (HR 1.15, 95\% CI 1.00$1.32)^{11}$. Despite an excess of haemorrhagic strokes (HR $1.42,95 \%$ CI 1.11-1.83), there was no significant difference in fatal or disabling strokes (HR 1.05, 95\% CI 0.961.16). There was significantly more discontinuation of the study drug among the aspirin plus dipyridamole group compared to the clopidogrel group $(29.1 \%$ versus $22.6 \%, P<0.001)$.

\section{SECTION 3: COST}

Cost differs substantially among the different treatment regimens. In Belgium, treatment is cheapest with Asaflow $^{\circledast}$ (80 mg ASA, $18 \mathrm{EUR} /$ patient/year), followed by Clopidogrel $\operatorname{Doc}^{\oplus}$ (75 mg clopidogrel, 106 EUR/ patient/year), followed by Aggrenox ${ }^{\odot}$ (25 mg ASA + $200 \mathrm{mg}$ dipyridamole, $207 \mathrm{EUR} /$ patient/year) and Plavix (75 mg clopidogrel, $291 \mathrm{EUR} /$ patient/year).

According to the University of York TAR team, aspirin plus dipyridamole would be the most cost effective therapy in the UK for patients not left disabled by their initial stroke and aspirin monotherapy for those left disabled, assuming a 2-year treatment duration and that the NHS is willing to pay 20,000-40,000 GBP per quality-adjusted life year (QALY) ${ }^{20}$.

After the introduction of generic clopidogrel, the National Institute for Health and Clinical Excellence (NICE) performed a new analysis in $2010^{3}$. They considered generic clopidogrel to be the most cost-effective therapy for patients with a history of stroke, whereas these conclusions could not be drawn for those with a history of a TIA, since clopidogrel was not licensed for this indication. According to the Assessment Group model, treatment of stroke patients with aspirin plus dipyridamole would result in an additional incremental cost effectiveness ratio (ICER) of 16,894 GBP per QALY gained compared to the next best strategy, and treatment with generic clopidogrel in an ICER of 13,558 GBP. The analysis provided by the manufacturers resulted in remarkably different outcomes, ranging from 237 GBP to 5,377 GBP with aspirin plus dipyridamole and 31,201 GBP to 114,628 GBP with branded clopidogrel, illustrating the dependence of the conclusions on the publisher's goodwill.

\section{SECTION 4: GUIDELINES}

International guidelines consider aspirin, as well as aspirin plus dipyridamole and clopidogrel monotherapy as acceptable options for initial therapy, grading it as a 1A Level of Evidence ${ }^{2-5,21}$. However, the results of the randomized controlled trials and their analysis are interpreted in different ways: there is neither consensus about the best option, nor about its level of evidence, nor about the dose of aspirin. Table 2 summarizes several guidelines.

\section{DISCUSSION}

\section{Section 1: Clinical effectiveness}

It has been suggested that relative superiority of aspirin plus dipyridamole in the ESPS- 2 trial might be due to the low dose of aspirin and that the observed difference might be due to a blood pressure lowering effect of dipyridamole ${ }^{22}$. Interestingly, these data on blood pressure were collected in the ESPS- 2 trial but not published. In a reply, Diener, a main investigator of the ESPS-2, MATCH and PRoFESS trials, tried to strengthen the position of aspirin plus dipyridamole, but avoided addressing this question. Nevertheless, it should be noticed that no other primary outcome (death, stroke and/or death) was significant.

Similarly, the ESPRIT study did not mention any other co-administered treatments although about $60 \%$ of the participants had hypertension and $47 \%$ had hyperlipidaemia ${ }^{7}$. Since risk reductions of $40-50 \%$ for blood pressure control and $20-30 \%$ for treatment with lipidlowering agents have been reported, these missing data are important for checking homogeneity among the subgroups and thus study validity ${ }^{23}$. For example, in patients with severe aortic plaque, statin therapy seems to be even more beneficial than antiplatelet drugs ${ }^{24}$. In addition, according to recent, large randomized trials, the statin beneficial effect does not seem to be related to the patient's lipid level ${ }^{25,26}$. Concerning the hypertension, a post-hoc substudy of 591 patients did not show any difference in blood pressure reduction after 15 months $^{27}$, but it must be noticed that difference in incidence of primary outcome in the ESPRIT study reached statistical significance only after 2-3 years, which is at least surprising: the risk of recurrence is highest within the first weeks. 
Table 2 Guidelines

\begin{tabular}{|c|c|c|}
\hline & Options & Recommendation \\
\hline AHA/ASA ${ }^{2}(2008)$ & Aspirin (50-325 mg); Aspirin plus dipyridamole; Clopidogrel & Aspirin plus dipyridamole \\
\hline $\mathrm{ESO}^{5}(2008)$ & Aspirin; Aspirin plus dipyridamole; Clopidogrel & Aspirin plus dipyridamole or clopidogrel \\
\hline $\operatorname{DGN}^{21}(2008)$ & Aspirin (100 mg); Aspirin plus dipyridamole; Clopidogrel & $\begin{array}{l}\text { If recurrence risk }<4 \% / y \text { : aspirin; If recurrence risk }>4 \% / y \text { : clopidogrel or aspirin plus } \\
\text { dipyridamole }\end{array}$ \\
\hline $\operatorname{NICE}^{3}(2010)$ & Aspirin; Aspirin plus dipyridamole; Clopidogrel & If ischaemic stroke: clopidogrel; If TIA: aspirin plus dipyridamole \\
\hline$\left.B C F\right|^{4}(2010)$ & Aspirin; Aspirin plus dipyridamole & Aspirin \\
\hline
\end{tabular}

The CAPRIE trial was a very well designed randomized trial. However, the outcome was not as convincing as the design: only a relative risk reduction of $8.7 \%$ for the primary cluster was achieved, whereas all secondary outcomes were statistically insignificant ${ }^{8}$. This overall effect was mainly ascribable to the peripheral arterial disease subgroup (RRR 23.8\%; 95\% CI 8.9-36.2, $P=0.0028)$, whereas the stroke subgroup was far away from statistical significance $(P=0.26)$, but the study was not powered for subgroup analysis. Despite these facts, post-hoc analyses have been performed in an attempt to show superiority of clopidogrel in various situations. In the collection of studies considered, non-negligible statistical flaws were detected. For example, Ringleb et al. concluded that the absolute benefit of clopidogrel seemed to be amplified in patients with pre-existing symptomatic atherosclerotic disease ${ }^{28}$. They provided an absolute risk reduction of $3.4 \%$ corresponding to a NNT of 29. This calculation has already been reported to be made based on an erroneous comparison with an imaginary placebo group ${ }^{29,30}$. However, no one noticed that even in this situation the confidence interval crossed the line of equivalence ( $95 \%$ CI-0.2 to 7.0). Likewise, the suggested amplified benefit in diabetic patients by Bhatt et al. was based on misinterpretations, concluding a consistent benefit among all individual and combined end points although all individual end points in diabetic patients were statistically not significant ${ }^{31}$.

Neither in the MATCH nor the CHARISMA trial, a benefit of adding clopidogrel to aspirin could be proven. In both studies no primary end point reached statistical significance. Furthermore, none of the 30 pre-specified subgroups in the MATCH trial could show any benefit ${ }^{9}$. A pre-specified substudy of the CHARISMA trial could not show any significant alteration in rate and functional severity even among high vascular risk patients ${ }^{32}$.

It would have been very interesting if the PRoFESS trial would have had an aspirin arm. However, because the differences between the study drugs are so small, the PRoFESS trial already had difficulties in recruiting enough subjects to allow a sound comparison between aspirin plus dipyridamole and clopidogrel with regard to risk reduction and adverse events.

The misleading effect of providing only relative risk reductions in conclusions is illustrated in figure 1 (only statistically significant outcomes are represented). This is an understandable attitude, since the absolute benefits are less convincing. It is interesting that there is a large difference between the assumed NNT of 67 in the ESPRIT trial and of 199 in the CAPRIE trial, whereas there is evidence of clinical equivalence between these drugs.

Of concern also is the issue of extrapolation. For example, Maasland et al. found that the included study subjects are only partially representative for patients in the Netherlands with only 25\% (MATCH trial) to 63\% (ESPS-2 trial) fulfilling the enrolment criteria of the ESPS-2, ESPRIT, CAPRIE, MATCH, and PRoFESS trials in their prospective study ${ }^{33}$. Mortality was higher in ineligible patients, but vascular events did not differ significantly.

Other issues are that rate of recurrence varies substantially according to TIA or stroke subtype, time to assessment and time to treatment, whereas most patients were included only several weeks after the qualifying event. Furthermore, it is important to remember that in the entire series of post-hoc analyses any finding of a significant subgroup could be due to the multiple comparison problem: increasing the number of post-hoc analyses increases the probability of so-called false discoveries.

A striking example of the need of critical analysis of study results and study result interpretations is the metaanalysis by risk performed by the same international leading experts as those contributing to the ESPRIT study group ${ }^{34}$. They erroneously concluded that superiority of aspirin plus dipyridamole compared to aspirin was found in all subgroups and was independent of baseline risk. However, nine of twenty-three subgroups according to risk factors and even three of five subgroups according to risk models presented statistically insignificant outcomes (e.g. DDT risk 4: HR 0.99, 95\% CI 
0.74-1.32). Interestingly, no significant reduction was found if randomization occurred within one month after the qualifying event.

\section{Section 2: Tolerance}

Serious adverse events are sometimes included in the primary end points (e.g. major bleeding complication in the ESPRIT study), making it more difficult to compare the results and to reclassify the weight of each agent. Due to the higher risk of major bleeding complications with the combination of aspirin plus clopidogrel compared to each agent alone, these combinations are not recommended unless specific indications are given (such as recent stenting). Not only serious adverse events should be taken into account: minor adverse events can lead to significant reduction in quality of life, challenging compliance and thus increasing risk of stroke recurrence in case of cessation. Especially the combination of aspirin plus dipyridamole causes such problems. Adverse events led in $8.6 \%$ of the patients in the aspirin group to study drug discontinuation, whereas this was as high as $15.9 \%$ in the aspirin plus dipyridamole group ${ }^{6}$. Recall the popularity of post-hoc analyses to claim any additional benefit of clopidogrel or aspirin plus dipyridamole compared to aspirin monotherapy. If we were to make a case of aspirin, then we could use the original data of the ESPS-2 trial to 'prove' superiority of aspirin monotherapy compared to aspirin plus dipyridamole by calculating the relative risk of treatment discontinuation due to any adverse event: then treatment with aspirin plus dipyridamole would increase that risk by $86 \%$ compared to aspirin monotherapy! Similar conclusions can be drawn for the comparison of aspirin plus dipyridamole and clopidogrel in the PRoFESS study: headache occurred in $30.2 \%$ in the first group, $10.2 \%$ in the latter ${ }^{11}$. This led to study drug discontinuation in the aspirin plus dipyridamole arm in $5.9 \%$ compared to $0.9 \%$ in the clopidogrel arm.

\section{Section 3: Combining effectiveness, adverse events, and cost}

A quick PubMed search could lead to the conviction of superiority of both aspirin plus dipyridamole and clopidogrel monotherapy compared to aspirin. Furthermore, the guidelines support this hypothesis. However, we suggest that in reality these superiorities are way less convincing. First, the absolute benefits are rather minimal compared to the relative benefits (cfr. a NNT of 199 for treatment with clopidogrel compared to aspirin). Second, the evidence is not as strong as often presented: although the RCTs are well designed, there are some shortcomings: sometimes data are incomplete (e.g. coadministered agents in the ESPRIT trial), or even incorrect (e.g. the meta-analysis by risk). Third, not only effectiveness is important but also tolerance profile, which clearly favours aspirin monotherapy and clopidogrel monotherapy compared to any dual therapy. Fourth, economic considerations favour aspirin. Fifth, there are broad differences in reported frequencies of both risk reductions and adverse events among different studies, which might compromise the relevance of the rather small observed differences within each study. This is also reflected by the large discrepancies in the costeffectiveness analyses provided by the different manufacturers. Hence, transposition of the minimal statistical significant differences into clinical significance is compromised.

Finally, table 3 illustrates the relativity of "relative superiority" by using the highest reported relative risk reductions (RRR) and plotting them against the relative

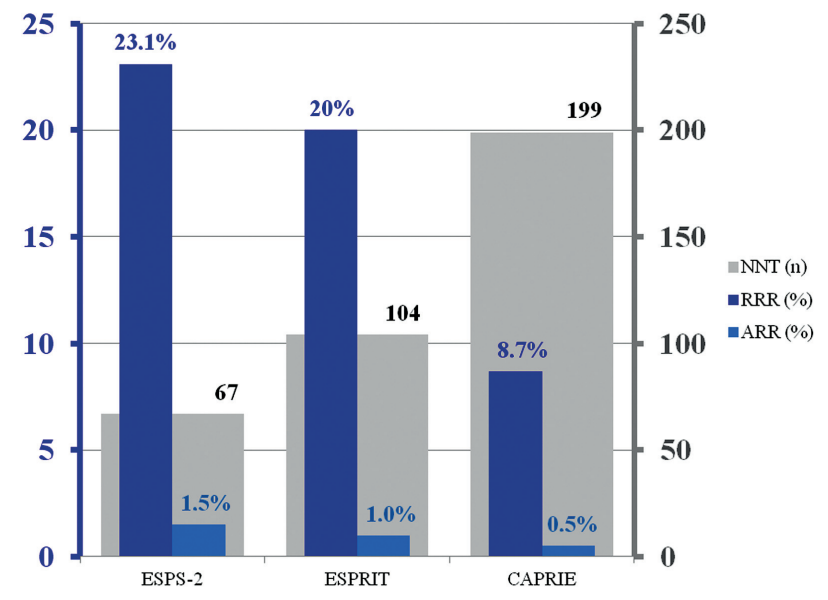

Fig. 1 RRR: relative risk reduction, ARR: absolute risk reduction, NNT: number needed to treat.

Table 3 Combining effectiveness, adverse events and cost

\begin{tabular}{|c|c|c|c|c|}
\hline & ASA+DIP $\leftrightarrow$ ASA $\left(E S P S-2^{6}\right)$ & ASA+DIP $\leftrightarrow$ CLO (PRoFESS $\left.{ }^{11}\right)$ & CLO $\leftrightarrow$ ASA $\left(\right.$ CAPRIE $\left.^{8}\right)$ & ASA $\leftrightarrow$ PLA $\left(\right.$ ESPS-2 $\left.{ }^{6}\right)$ \\
\hline Effectiveness: RRR (\%) & $23 \%$ & $\sim$ & $9 \%$ & $18 \%$ \\
\hline Non-compliance: RRI (\%) & $86 \%$ & $54 \%$ & $\sim$ & $11 \%$ \\
\hline Additional cost (EUR/pt/y) & $189 €$ & $101 €$ & $88 €$ & $18 €$ \\
\hline
\end{tabular}

ASA: aspirin, DIP: dipyridamole, CLO: clopidogrel, PLA: placebo, pt: patient, RRI: relative risk increase, RRR: relative risk reduction, y: year. 
increased risk (RRI) of study drug discontinuation due to any adverse event, and the amount of the annual additional cost per patient treated with the study drug in comparison with the control drug in Belgium.

\section{CONCLUSIONS}

Although statistical superiority of both aspirin plus dipyridamole and clopidogrel monotherapy compared to aspirin monotherapy has been reported by large randomized trials, clinical superiority is at best minimal. Furthermore, if tolerance profile is included in judge- ment of efficiency, then aspirin monotherapy or clopidogrel monotherapy should be advised as the first-line therapy, since both aspirin plus dipyridamole and aspirin plus clopidogrel carry a higher risk of adverse events and non-compliance. If, besides effectiveness and adverse events also economic considerations are taken into account, then aspirin monotherapy is the best choice. Therefore, aspirin should retain its position as the main antiplatelet strategy for secondary prevention after TIA or non-cardioembolic ischaemic stroke.

CONFLICT OF INTEREST: none declared.

\section{REFERENCES}

1. Lazarro MA, Malhotra K, Mohammad YM. The role of antithrombotics in secondary stroke prevention. Semin Neurol 2010; 30: 492-500.

2. Adams RJ, Albers G, Alberts MJ, Benavente $O$ Furie K, Goldstein LB, Gorelick P, Halperin J, Harbaugh R, Johnston SC, Katzan I, Kelly-Hayes M, Kenton EJ, Marks M, Sacco RL, Schwamm LH; American Heart Association; American Stroke Association. Update to the AHA/ASA recommendations for the prevention of stroke in patients with stroke and transient ischemic attack.

Stroke 2008; 39: 1647-52.

3. Clopidogrel and modified-release dipyridamole for the prevention of occlusive vascular events (review of technology appraisal guidance 90). National Institute for Health and Clinical Excellence website. http:// www.nice.org.uk/nicemedia/ live/13285/52030/52030.pdf. December 2010 (accessed 5 April 2012).

4. Secundaire preventie van cerebrovasculaire accidenten. Transparantiefiche 2010. http:// www.bcfi.be/pdf/tft/TN_CVA.pdf. Belgisch Centrum voor Farmacotherapeutische Informatie. May 2007 (accessed 5 April 2012) [in Dutch].

5. Guidelines for management of ischaemic stroke and transient ischaemic attack 2008. European Stroke Organisation website. http:// www.eso-stroke.org/pdf/ESO\%20 Guidelines_update_Jan_2009.pdf. (accessed 5 April 2012).

6. Diener HC, Cunha L, Forbes C, Sivenius J, Smets P, Lowenthal A. European Stroke Prevention Study. 2. Dipyridamole and acetylsalicylic acid in the secondary prevention of stroke. J Neurol Sci 1996; 143: 1-13.

7. ESPRIT Study Group, Halkes PH, van Gijn J, Kappelle LJ, Koudstaal PJ, Algra A. Aspirin plus dipyridamole versus aspirin alone after cerebral ischaemia of arterial origin (ESPRIT): randomised controlled trial.

Lancet 2006; 367: 1665-73.

8. CAPRIE Steering Committee. A randomised, blinded, trial of clopidogrel versus aspirin in patients at risk of ischaemic events (CAPRIE). Lancet 1996; 348: 1329-39.

9. Diener HC, Bogousslaversusky J, Brass LM, Cimminiello C, Csiba L, Kaste M, Leys D, Matias-Guiu J, Rupprecht HJ; MATCH investigators. Aspirin and clopidogrel compared with clopidogrel alone after recent ischaemic stroke or transient ischaemic attack in high-risk patients (MATCH): randomised, double-blind, placebo-controlled trial. Lancet 2004; 364: 331-7.

10. Bhatt DL, Fox KA, Hacke W, Berger PB, Black HR, Boden WE, Cacoub P, Cohen EA, Creager MA, Easton JD, Flather MD, Haffner SM, Hamm CW, Hankey GJ, Johnston SC, Mak KH, Mas JL, Montalescot G, Pearson TA, Steg PG, Steinhubl SR, Weber MA, Brennan DM, Fabry-Ribaudo L, Booth J, Topol EJ; CHARISMA investigators. Clopidogrel and aspirin versus aspirin alone for the prevention of atherothrombotic events. N Engl J Med 2006; 354: 1706-17.

11. Sacco RL, Diener HC, Yusuf $S$, Cotton $D$, Ounpuu S, Lawton WA, Palesch Y, Martin RH, Albers GW, Bath P, Bornstein N, Chan BP, Chen ST, Cunha L, Dahlöf B, De Keyser J, Donnan GA, Estol C, Gorelick P, Gu V Hermansson K, Hilbrich L, Kaste M, Lu C, Machnig T, Pais P, Roberts R, Skvortsova V, Teal P, Toni D, Vandermaelen C, Voigt T, Weber M, Yoon BW; PRoFESS Study Group. Aspirin and extended-release dipyridamole versus clopidogrel for recurrent stroke. NEngl J Med 2008; 359: 1238-51.

12. Antithrombotic Trialists' Collaboration. Collaborative meta-analysis of randomised trials of antiplatelet therapy for prevention of death, myocardial infarction, and stroke in high risk patients. BMJ 2002; 324: 71-86.

13. Hankey GJ, Warlow CP. Treatment and secondary prevention of stroke: evidence, costs and effects on individuals and populations. Lancet 1999; 354: 1457-63.

14. De Schryver EL, Algra A, van Gijn J. Dipyridamole for preventing stroke and other vascular events in patients with vascular disease. Cochrane Database Syst Rev 2007; 3 CD001820.

15. Verro P, Gorelick PB, Nguyen D. Aspirin plus dipyridamole versus aspirin for prevention of vascular events after stroke or TIA: a meta-analysis. Stroke 2008; 39: 1358-63.

16. Thijs V, Lemmens R, Fieuws S. Network meta-analysis: simultaneous meta-analysis of common antiplatelet regimens after transient ischaemic attack or stroke. Eur Heart J 2008; 29: 1086-92.

17. Serebruany VL, Steinhubl SR, Berger PB, Malinin Al, Baggish JS, Bhatt DL, Topol EJ. Analysis of risk of bleeding complications after different doses of aspirin in 192,036 patients enrolled in 31 randomized controlled trials. Am J Cardiol 2005; 95: 1218-22.

18. McQuaid KR, Laine L. Systematic review and meta-analysis of adverse events of low-dose aspirin and clopidogrel in randomized controlled trials. Am J Med 2006; 119: 624-38.

19. Sudlow CL, Mason G, Maurice JB, Wedderburn CJ, Hankey GJ. Thienopyridine derivates versus aspirin for preventing stroke and other serious vascular events in high vascular risk patients. Cochrane Database Syst Rev 2009; 4: CD001246.

20. Jones L, Griffin S, Palmer S, Main C, Orton V, Sculpher M, Sudlow C, Henderson R, Hawkins N, Riemsma R. Clinical effectiveness and cost-effectiveness of clopidogrel and modified-release dipyridamole in the secondary prevention of occlusive vascular events : a systematic review and economic evaluation.

Health Technol Assess 2004; 8(38): iii-iv, 1-196.

21. Diener HC. Primär- und Sekundärprevention der zerebralen Ischämie. Gemeinsame Leitlinie der DGN und der Deutschen Schlaganfallgesellschaft (DSG). (Deutsche Gesellschaft für Neurologie website). [in German]. http://www.dgn.org/images/ stories/dgn/leitlinien/LL2008/II08kap_024. pdf. (Accessed 6 April 2012).

22. Warlow CP. Aspirin should be first-line antiplatelet therapy in the 
secondary prevention of stroke. Stroke 2002; 33: 2137-40.

23. Spence JD. Secondary stroke prevention. Nat Rev Neurol 2010; 6: 477-86.

24. Tunick PA, Nayar AC, Goodkin GM, Mirchandani S, Francescone S, Rosenzweig BP, Freedberg RS, Katz ES, Applebaum RM, Kronzon I; NYU Atheroma Group. Effect of treatment on incidence of stroke and other emboli in 519 patients with severe thoracic aortic plaque. Am J Cardiol 2002; 90: 1320-5.

25. Bulbulia R, Bowman L, Wallendszus K, Parish S, Armitage J, Peto R, Collins R; Heart Protection Study Collaborative Group. Effects on 11-year mortality and morbidity of lowering LDL cholesterol with simvastatine for about 5 years in 20,536 high risk individuals: a randomised controlled trial. Lancet 2011; 378: 2013-20.

26. Everett BM, Glynn RJ, MacFadyen JG, Ridker PM. Rosuvastatin in the prevention of stroke among men and women with elevated levels of C-reactive protein: Justification for the Use of Statins in Prevention: an Intervention Trial Evaluating Rosuvastatin (JUPITER). Circulation 2010; 121: 143-50.
27. De Schryver EL; ESPRIT Study Group. Dipyridamole in stroke prevention: effect of dipyridamole on blood pressure. Stroke 2003; 34: 2339-42.

28. Ringleb PA, Bhatt DL, Hirsch AT, Topol EJ, Hacke W; Clopidogrel Versus Aspirin in Patients at Risk of Ischemic Events Investigators. Benefit of clopidogrel is amplified in patients with a history of ischemic events. Stroke 2004; 35: 528-32.

29. Lewis SC, Warlow CP. There is no evidence that the benefit of clopidogrel over aspirin is amplified in patients with a history of ischemic events. Stroke 2004; 35: 2241.

30. Algra A, van Gijn J, Kapelle LJ, Koudstaal PJ, Stam J, Vermeulen M. Creative mathematics with clopidogrel; exaggeration of the preventive effect by manufacturer. Ned Tijdschr Geneeskd 1999; 143: 2479 [in Dutch].

31. Bhatt DL, Marso SP, Hirsch AT, Ringleb PA, Hacke W, Topol EJ. Amplified benefit of clopidogrel versus aspirin in patients with diabetes mellitus. Am J Cardiol 2002; 90: 625-8.

32. Hankey GJ, Hacke W, Easton JD, Johnston SC Mas JL, Brennan DM, Bhatt DL, Fox KA
Topol EJ; CHARISMA Trial Investigators. Effect of clopidogrel on the rate and functional severity of stroke among high vascular risk patients: a prespecified substudy of the Clopidogrel for High Atherothrombotic Risk and Ischemic Stabilization,

Management and Avoidance (CHARISMA) trial. Stroke 2010; 41: 1679-83.

33. Maasland L, van Oostenbrugge RJ, Franke CF, Scholte Op Reimer WJ, Koudstaal PJ, Dippel DW; Netherlands Stroke Survey Investigators. Patients enrolled in large randomized clinical trials of antiplatelet treatment for prevention after transient ischemic attack or ischemic stroke are not representative of patients in clinical practice: the Netherlands Stroke Survey. Stroke 2009; 40: 2662-8.

34. Halkes PH, Gray LJ, Bath PM, Diener HC Guiraud-Chaumeil B, Yatsu FM, Algra A. Dipyridamole plus aspirin versus aspirin alone in secondary prevention after TIA or stroke: a meta-analysis by risk. J Neurol Neurosurg Psychiatry 2008; 79 : 1218-23. 